\title{
Research on micropile foundation of transmission tower on soft soil area
}

\author{
WANG Hua Juan
}

\author{
Shandong Electric Power Engineering Consulting Institute corp., Ltd., Jinan, Shandong, China
}

\begin{abstract}
KEYWORD: Transmission tower; Large-diameter pile; Micropile; Soft soil
ABSTRACT: With the rapid development of ultra-high voltage power grid, plenty of transmission towers are built on soft soil area and the foundation of tower should be designed for economical and security reasons. The mechanism and application of the new micropiles foundation are discussed, which have many advantages in design and construction stage, such as accurate calculation, loading transfer clearly, convenient installation, easily installment within confined spaces and cost reduction. Traditional large-diameter pile foundation is a main way on soft soil layer in the past fifty years. By mechanism analysis, some disadvantages had been achieved and the kind of foundation is inadaptable in many engineering site. By a ultra-high voltage power grid project, the transmission tower foundation is designed using the two differential methods and the fouandtion plans had been drawn and quantities comparison analysis had been conducted. Some meaningful conclusions proposed which can provide a reference for similar project.
\end{abstract}

\section{INTRODUCTION}

Soft soil area accounts for a large area of our country, especially in the economic developed area, such as southeast of China. Now with the rapid development of national economy of China, the Yellow River delta plain economy obtained the swift and violent development and the power infrastructure investment is increasing in recent years. As China's most young land, the soil layer of Yellow River delta is softer and more liquefiable than other area in Shandong province. Referring to silt and silt soil, soft soil is the late quaternary in the coastal areas of littoral facies, lagoon facies, delta facies and drowned valley, inland plains and mountainous area of lake facies and shock pluvial swamp equal hydrostatic or very slow deposition, water environment and formed by the biochemical effect of saturated soft clay. Composition and state of the soft soil is determined by its formation environment.

Generally the soft soil is given priority to with grey of the appearance, natural void ratio is greater than or equal to 1.0, and the natural water content is greater than the liquid limit of fine grained soils. The mechanical properties characteristics of soft soil are high natural moisture content and void ratio, high compressibility, low shear strength, low coefficient of consolidation, high sensitivity and disturbance of consolidation, poor permeability, soil layers distributed complex. Since it formed in the water which is not unobstructed, still water basin which is saturation of oxygen, this kind of soil is mainly composed of clay and silt of tiny particles.

For transmission line tower foundation in soft soil foundation, according to the geological conditions, usually adopt reinforced concrete raft foundation, pile foundation forms, etc. Transmission line tower foundation in soft soil area should not only meet the requirements of bearing capacity, but also to meet the total settlement and uneven deformation of foundation. In general, the higher cost of foundation construction on soft soil ground, the quantity is larger.Therefore, in the design of the tower foundation in soft soil foundation, it is reasonable to adopt the new type, the basis of the work is in order to reduce the construction difficulty and reduce damage to the natural environment, reduce the project cost at last.

Ultra-high voltage power grid is refers to a $1000 \mathrm{kv}$ transmission network backbone network frame, ultra-high voltage grid and the grid and ultra high voltage dc high voltage direct current transmission and distribution network composed of hierarchical, partition, clear structure of modern power grid. Its prominent feature is the large capacity, long distance transmission and at present, the Chinese to develop ultra-high voltage transmission technology independent innovation and independent 
research and had fully mastered the key technology of ultra-high voltage construction, including the steel tower group, tension stringing, substation foundation construction and substation main equipment installation and so on. The engineering construction will go through soft soil area of Yellow River delta in the province of shandong and the new type foundation of micropile should be researched in this thesis.

\section{CHARACTERISTICS AND APPLICATION OF MICROPILE}

Pile foundation is consisted and connected with the pile and pile cap on the top of pile. As an ancient type of pile foundation, pile foundation technology has experienced thousands of years of development process. Both material and type of pile, pile driving machinery and construction method has a great development and formed a modern infrastructure system. With the development of pile foundation, micropile technology had been invented and developed by Murthy et al. 2002. The miniature pile diameter less than $300 \mathrm{~mm}$ in general, generally refers to pile slenderness ratio of more than 30 small diameter pile type. The kind of pile was put forward by the Italian f. lizzi in the 1950s by, and developed by Fondedile company first. Of late, technological advancement in machinery has made it possible for micropile of much greater diameters to be constructed.

In the past micropile was only used when the ground conditions warranted it because of considerations on cost and speed by Juran et al. 1999. Micropile is slow because of the drilling and flushing process, it might takes minutes or hours to complete. But the trend is such, micropile is now gaining greater popularity and getting wider acceptance because of the requirement to comply with no noise and low vibration regulations, expecially in congested environments. These micropiles can extend to depths of 200 feet and can take loads as small as 3 tons or as high as 200 tons.

Generally, micropiles are applicable when there are problems with using conventional deep foundation systems by Dash \& Pise (2003). These problem conditions include: obstructions, adjacent structures, limited access job sites, and other shaky areas like caves, sinkholes, underground rivers. For example, micropiles are commonly the preferred foundation choice in the challenging areas that feature nearby buildings and difficult access.

Micropiles are an ideal pile for complex sites where low vibration or low noise levels are required by Moayed \& Naeini (2012), or where limited access such as low headroom and drilling is difficult. Other site conditions that make micropiles attractive are: obstructions, large cobbles or boulders, nearby sensitive structures, karst topography or high groundwater conditions. The unique characteristics of micropiles make them a perfect solution when other deep foundation methods are not suitable.

The advantages of micropiles are shown as follows:

(1) Creates a pile with a relatively high axial load capacity

(2) Works in compression and tension

(3) Lightweight rotary percussive equipment can be used

(4) Easily installed within confined spaces

(5) No harmful vibrations or noise to surrounding structures

(6) Minimal spoil generation on contaminated sites

Based on those advantages, the applications of micropile are extesive, such as:

(1) Structural Support of Directly Loaded Piles

(2) New Foundatiions

(3) Underpinning of Existing Structures

(4) Seismic Retrofitting

(5) Reinforcement for Slope Stabilization and Settlement Reduction

(6) Support of Excavation - Soldier Piles

(7) Permanent Retaining Walls

The application pictures of micropiles are shown as Figure1 and Figure 2. It can be seen that the application of micropile is very extensive and more complex engineering problems had been solved by Tan et al. 2000. The United States and some European countries have developed a minia- 
ture pile special components, and formulate the corresponding standards. These components are not only improves the miniature pile construction technology and its reliability has been improved significantly.

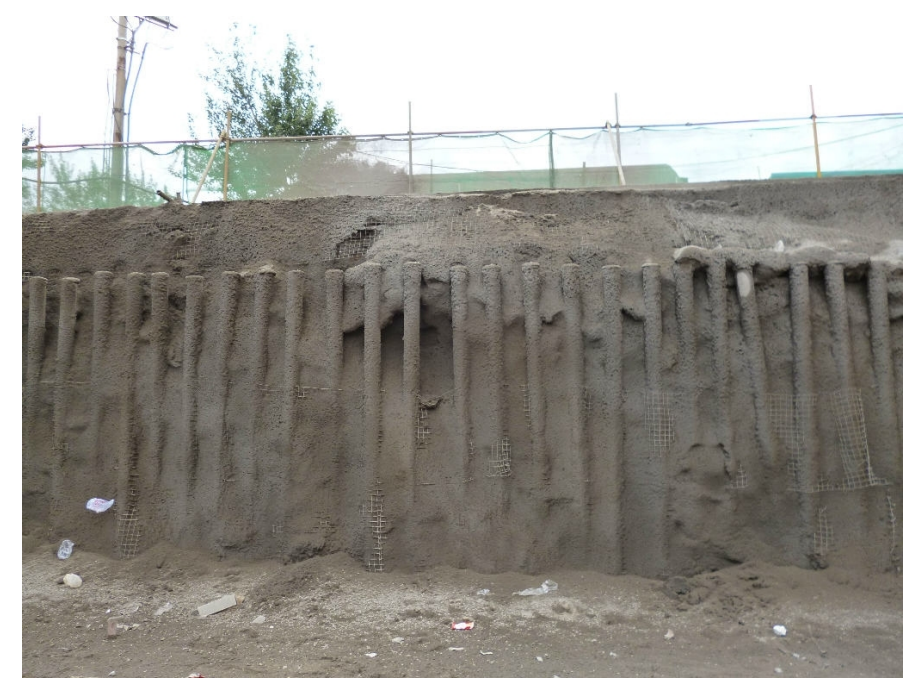

Figure 1. The application of micropile as soldier piles of excavation support

So far, the micro piles were used in more than 3000 engineering projects. Today, micro pile is accepted by the engineering field and the pile type is considered to be valuable, especially in the case of foundation reinforcement and strengthening, but the research on micro pile is still less.

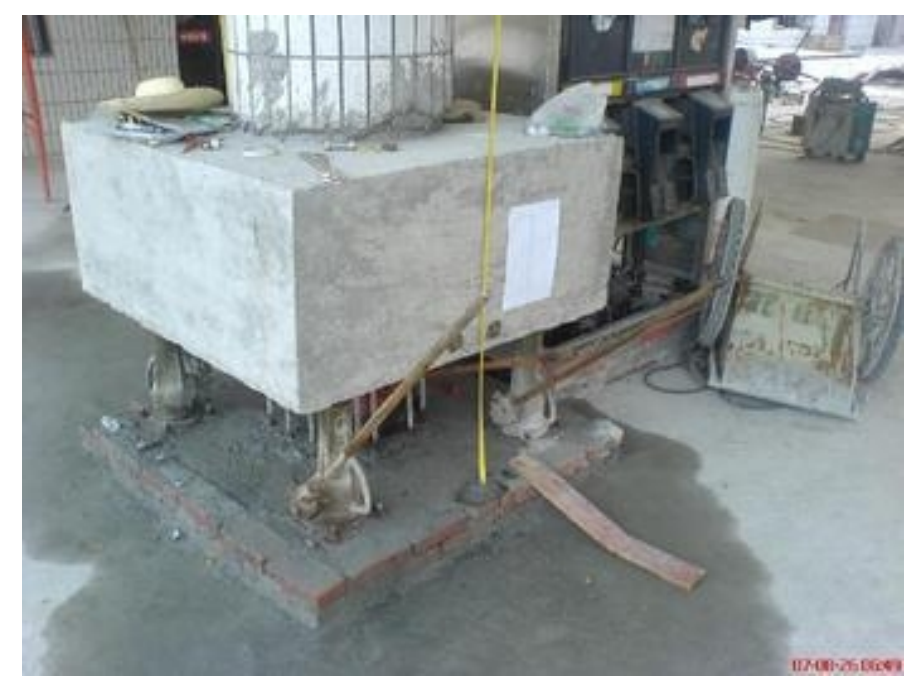

Figure 2. The application of micropile as underpinning of Existing Structures

\section{FOUNDATON SCHEME COMPARISON}

One large-span tangent tower for ultra-high voltage power grid is selected for foundation scheme comparison. Traditional foundation is large-diameter piles, which is constructed by drilling machine to drill a hole, and casting of concrete pile in the hole. In this scheme comparison, the largediameter pile and micropile are studied and analyzed. According to a real project, calculation and comparison analysis are conducted and shown as follows: 
Large-diameter pile foundation: the diameter of pile is $1200 \mathrm{~mm}$ and the length is $25 \mathrm{~m}$. According to geotechnical investigation report and design code, the bearing capacity of the pile is reached $2000 \mathrm{kN}$. The plan of pile foundation is shown as Figure 3.

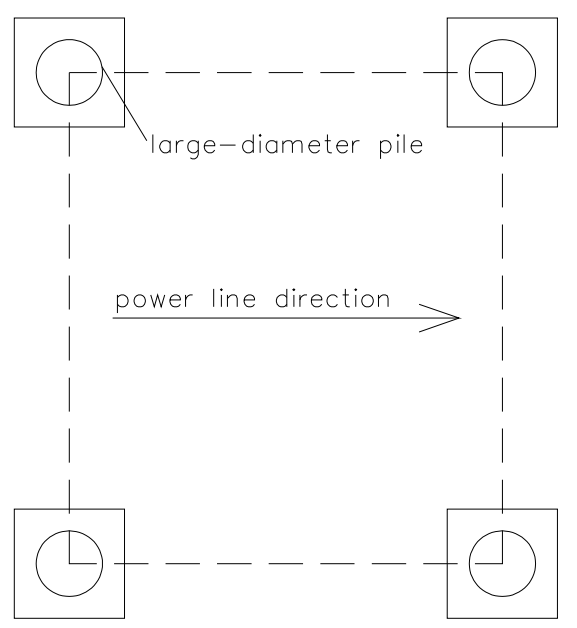

Figure 3. The plan of pile foundation

Micropile foundation: five micropiles are designed in each column of tower. The diameter of micropile is $220 \mathrm{~mm}$ and cement mortar strength is $\mathrm{C} 30$, which bearing capacity is reached to $400 \mathrm{kN}$ with the length of micropile is $23 \mathrm{~m}$. Five cushion cap are designed in this project and the layout plan is shown as Figure 4-5.

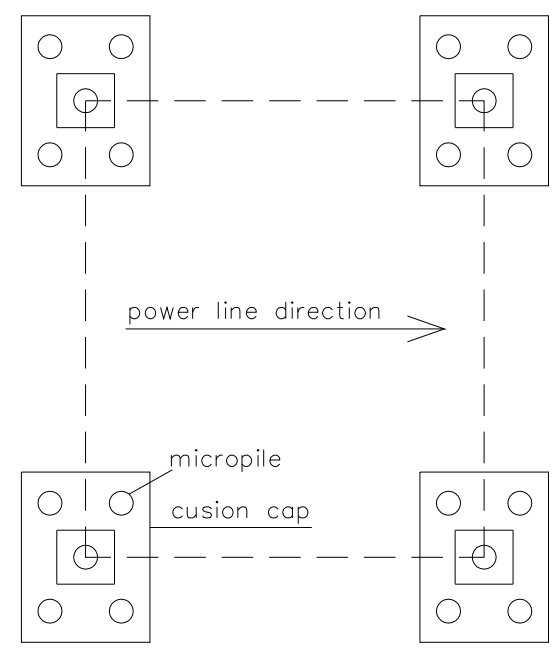

Figure 4. The plan of miropile foundation 


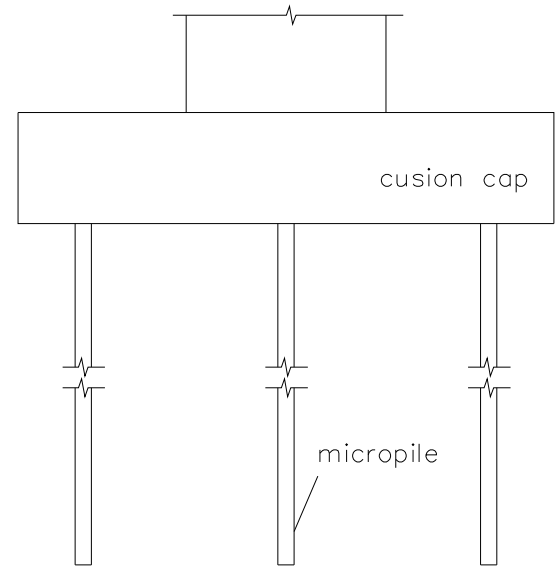

Figure 5. The The vertical section of micropile foundation

The comparison of bill of quantities is conducted. Through the comparison, the quantities of concrete and steel of micropile foundation is smaller than reinforced concrete large-diameter pile foundation, only little of cement paste and gravel are needed. On the whole, the micropile foundation is superior to pile foundation and get more and more used in engineering.

Compared with the general foundation on soft soil ground form, micropile foundation can effectively reduce the engineering quantities, reduce the construction difficulty and the base covers. Miniature pile construction cost compared with the general foundation form on soft soil foundation is low, especially suitable for as the foundation of the tower on soft soil foundation and has broad application prospects.

\section{FURTHER RESEARCH PROBLEMS}

Bearing capacity of micropile foundation calculation need to consider the limited bearing capacity of single pile and pile group effect, but is very difficult to determine the pile group effect coefficient because the pile group effect coefficient changed with the pile diameter, pile spacing, pile length, pile numbers and pile caps set mode. Considering pile group effect, will make the results of calculation micropile bearing capacity more reliable and makes engineering design more economic and reasonable.

The influence of the single pile and pile group foundation bearing capacity and resistance to capsizing induced by first and secondary grouting is qualitative description and had not been fully researched. So grouting effect researc should be conducted and solved the selection of grouting material, determine the form of grouting, grouting process, grouting pressure and grouting quantity. Therefor the studies can provide strong technical support for promotion and application of the micro piles and had strong theoretical and practical significance.

The complexity of micropile structure makes it uplift, press and horizontal tipping load pull alone or combination of micropile foundation under the action of pile caps, and the interaction between pile and soil of law and its working characteristics parameters become very complex, and eventually lead to the theoretical calculation of difficulties, especially composite inclined pile foundation under the action of lateral horizontal force stability against overturning calculation problem is particularly prominent.

\section{CONCLUSIONS}

In this paper, the characteristics and application of micropile had been discussed. With the construction of ultra-high voltage power grid, more and more power transmission tower will be build in soft soil area. Based on a project at Yellow River delta, the quantities of two kind of foundation had been achieved and comparison analysis shows that the micropile has more advantages and should be extensively applied in the future. 


\section{REFERENCES}

[1] Dash B. K. \& Pise P. J. 2003. Effect of compressive load on uplift capacity of model pile, Journal of Geotechnical \& Geoenvironmental Engineering, ASCE, 129(11): 987-992.

[2] Juran I., Bruce D. A., Dimillio A. \& Benslimane A. 1999. Micropiles: the state of practice. Part II: design of single micropiles and groups and networks of micropiles. Ground Improvement, 3(3): 89-110.

[3] Moayed R. Z. \& Naeini S. A. 2012. Imrovement of Loose Sandy Soil Deposits using Micropiles, KSCE Journal of Civil Engineering, 16 (3):334-340.

[4] Murthy B. R. S., Babu G. L. S. \& Srivivas A.2002. Analysis of bearing capacity improvement using micropiles, Ground Improvement, 6(3): 121-128.

[5] Tan S. A., Luo S. Q. \& Yong K. Y. 2000. Simplified models for soil-nail lateral interaction. Ground Improvement, 4(4): 141-152. 